Short Note

\title{
Tipburn Severity and Calcium Distribution in Lisianthus (Eustoma Grandiflorum (Raf.) Shinn.) Cultivars under Different Relative Air Humidity Conditions
}

\author{
Takanori Kuronuma ${ }^{1}$, Yua Watanabe ${ }^{2}$, Masaya Ando ${ }^{1}$ and Hitoshi Watanabe ${ }^{1, *}$ \\ 1 Center for Environment, Health and Field Sciences, Chiba University, 6-2-1 Kashiwa-no-ha, Kashiwa-city, \\ Chiba 277-0882, Japan; t.kuronuma@chiba-u.jp (T.K.); m-ando@chiba-u.jp (M.A.) \\ 2 Faculty of Horticulture, Chiba University, 648 Matsudo, Matsudo-city, Chiba 271-8510, Japan; \\ yuaw9543@gmail.com \\ * Correspondence: hwatanabe@faculty.chiba-u.jp; Tel.: +81-47-137-8106
}

Received: 8 September 2018; Accepted: 4 October 2018; Published: 5 October 2018

\begin{abstract}
Tipburn is a major problem for the production of lisianthus (Eustoma grandiflorum (Raf.) Shinn.) cultivars. Relative air humidity is regarded as a key environmental factor affecting tipburn severity in commercial crops. However, there are limited studies comparing the occurrence of tipburn and calcium (Ca) distribution in lisianthus cultivars under different relative air humidity conditions. Accordingly, we investigated the effect of relative air humidity on tipburn severity, transpiration rate, and Ca content in seven lisianthus cultivars. Under a high humidity treatment (70\%), only two cultivars ("Voyage pink" (VP) and "Azuma-no-kaori" (AK)) showed significantly higher tipburn severity than those under a low humidity treatment $(50 \%)$, which suggests that high humidity conditions do not always increase tipburn severity in lisianthus. Transpiration rates of all cultivars, except for AK, were either significantly lower under the high humidity treatment than under the low humidity treatment, or did not vary significantly between the treatments. In contrast, total Ca concentrations in all cultivars, except for "Piccolosa snow" (PS), were significantly higher under the high humidity treatment than under the low humidity treatment. These results suggest that $\mathrm{Ca}$ acquisition and distribution in lisianthus cultivars are strongly influenced by Ca uptake from root pressure.
\end{abstract}

Keywords: Ca concentration; Ca deficiency; relative growth rate; root pressure; transpiration rate

\section{Introduction}

Lisianthus (Eustoma grandiflorum (Raf.) Shinn.) is an ornamental plant originating from the southern United States and Northern Mexico. It is mainly supplied in the form of cut flowers. In Japan, lisianthus is produced year-round [1], and was ranked fifth in terms of the total wholesale value of cut flowers in 2017. However, the occurrence of tipburn in several lisianthus cultivars is a serious problem, because it diminishes plant quality and marketability.

Tipburn appears on the apices of young leaves, and is generally regarded as a symptom of calcium (Ca) deficiency. At first, the leaf margins are deformed, then the leaf tips become chlorotic and eventually die. The occurrence of tipburn is influenced by various environmental factors, including light [2,3], temperature [4,5], and air flow [6,7]. In particular, it has been shown that relative air humidity has a large effect on tipburn incidence, because Ca transport in a plant body depends on transpiration (water flow) [8-10]. 
Kuronuma et al. [11] reveal that the occurrence of tipburn in lisianthus cultivars is caused mainly by the inability of the plant to translocate sufficient $\mathrm{Ca}$ to the tip of upper leaves. However, few studies have compared tipburn severity and Ca distribution in lisianthus cultivars under different relative air humidity conditions.

Therefore, to elucidate the influence of relative air humidity on the occurrence of tipburn and Ca distribution in lisianthus cultivars, we investigated the tipburn severity and Ca content of seven cultivars under low (50\%) and high (70\%) air humidity conditions.

\section{Materials and Methods}

\subsection{Plant Material}

Seven lisianthus cultivars were used in this study (Table 1). Seeds were sown in plug flats (406 cells per tray) filled with seedling propagation medium (Metro Mix; Sun Gro Horticulture, Agawam, MA, United States). The seeded trays were maintained in a germination room at $24{ }^{\circ} \mathrm{C}$ under a $14 / 10 \mathrm{~h}$ light/dark photoperiod. After two weeks, the trays were transferred to a totally controlled environmental system (phytotron) and the plants were grown under the following conditions: $25^{\circ} \mathrm{C}$ (light period) and $20{ }^{\circ} \mathrm{C}$ (dark period), $60 \pm 5 \%$ humidity, $400 \mathrm{ppm} \mathrm{CO} \mathrm{CO}_{2}$ concentration, and $14 \mathrm{~h}$ light $(225 \pm 25 \mu \mathrm{mol}$ $\mathrm{m}^{-2} \mathrm{~s}^{-1}$ ) and $10 \mathrm{~h}$ dark. An irrigation system in the phytotron supplied a nutrient solution (62 ppm $\mathrm{NO}_{3}-\mathrm{N}, 4.6$ ppm NH $\mathrm{NH}_{4}-\mathrm{N}, 10.2$ ppm PO $\mathrm{PO}_{4}-\mathrm{P}, 104$ ppm K, 16 ppm SO${ }_{4}-\mathrm{S}, 40$ ppm Ca, 12 ppm Mg, 2.8 ppm Fe, $1.6 \mathrm{ppm} \mathrm{B}, 0.8 \mathrm{ppm} \mathrm{Mn}, 0.08 \mathrm{ppm} \mathrm{Zn}, 0.04 \mathrm{ppm} \mathrm{Cu}$, and $0.04 \mathrm{ppm} \mathrm{Mo}$ ) by bottom watering for $15 \mathrm{~min}$. Five weeks after transfer to the phytotron, the plugs were transplanted into $0.25 \mathrm{~L}$ polyethylene pots filled with Metro Mix.

Table 1. Lisianthus cultivars used in the present study.

\begin{tabular}{ccc}
\hline Cultivars & Abbreviations & Selling Agencies \\
\hline "Azuma-no-kaori" & AK & Sakata Seed Corporation \\
"Bolero white" & BW & Miyoshi Co., Ltd. \\
"Celeb green" & CG & Sumika Agrotech Co.,Ltd. \\
"Diamond peach" & DP & Miyoshi Co., Ltd. \\
"Fuyu-no-maria" & FM & Sakata Seed Corporation \\
"Piccolosa snow" & PS & Sakata Seed Corporation \\
"Voyage pink" & VP & Sakata Seed Corporation \\
\hline
\end{tabular}

\subsection{Experimental Design}

To investigate tipburn severity and Ca concentrations in the seven cultivars under low and high air humidity conditions, individuals of the seven cultivars were assigned randomly to either a low or high air humidity treatment. Plants under the low air humidity treatment were maintained in the phytotoron, where relative air humidity was maintained at $50 \pm 5 \%$ using a dehumidifier (MJ-120LX; Mitsubishi Electric Corporation, Tokyo, Japan). Plants under the high air humidity treatment were maintained in the phytotoron at a relative air humidity of $70 \pm 5 \%$ using a dehumidifier (KJ-373 HE; CCP Co., Ltd., Tokyo, Japan). Environmental conditions, except for humidity, in the phytotoron were the same as above. At the start of the experiment, four pots were randomly sampled from all seven cultivars, and this experiment was replicated three times (randomized blocks model). Thus, a total of 12 pots were randomly sampled from all seven cultivars, and plant dry weights were measured. No tipburn was observed in any of the cultivars at that stage. Ten weeks later, all 12 pots (4 pots $\times 3$ replications) were randomly sampled from all seven cultivars, and they were evaluated for tipburn severity, plant growth rate, transpiration rate, and Ca distribution. 


\subsection{Tipburn Severity}

Whole leaves were ranked from 0 to 1 using an arbitrary tipburn severity index (0: no symptom; 0.2: deformed leaf margins; 0.5 : leaf tip chlorosis; 1 : leaf tip necrosis). Tipburn severity in each plant was defined as

$$
\text { Tipburn severity }=\sum\{(\text { severity indices } \times \text { leaf number }) / \text { whole leaves number per pot }\} \times 100
$$

\subsection{Plant Growth Rate}

The relative growth rate (RGR) was calculated using the following equations, based on the random pairing method [12], because it is well known that plant growth rate significantly influences tipburn severity and incidence [13-15].

$$
\operatorname{RGR}=\left(\ln W_{2}-\ln W_{1}\right) /\left(T_{2}-T_{1}\right)
$$

where $W_{1}$ and $W_{2}$ are the whole-plant dry weights at times $T_{1}$ (start of the experiment) and $T_{2}$ (end of the experiment), respectively.

\subsection{Transpiration Rate}

To investigate the effect of relative air humidity on plant water flow, six pots ( 3 pots $\times 2$ replications) per cultivar were selected, and their transpiration rate was measured for a leaf having the maximum area in a plant, using a Li-6400 (LI-COR, Lincoln, NE, United States) with a light-emitting diode light source. Measurement conditions were as follows: $25{ }^{\circ} \mathrm{C}$, relative air humidity-matched treatment conditions (low: $50 \pm 5 \%$; high: $70 \pm 5 \%$ ), $400 \mathrm{ppm} \mathrm{CO}_{2}$ concentration, and $250 \mu \mathrm{mol} \mathrm{m}^{-2} \mathrm{~s}^{-1}$ photosynthetic photon flux density.

\subsection{Ca Distribution}

Ca concentrations in the leaves and the other parts (stems and roots) were measured. To determine the vertical and horizontal Ca distributions for each cultivar, the leaves of each plant were segregated into the upper one-third from the top nodes (upper leaves) and the lower two-thirds (lower leaves). The Ca concentrations for the upper leaves were measured separately in the top one-fifth (leaf tip) and the remaining four-fifths (leaf base). Ca concentration was determined using a Z-5300 polarized Zeeman atomic absorption spectrophotometer (Hitachi, Ltd., Tokyo, Japan). In addition, to calculate the total Ca concentration, we quantified the whole-plant $\mathrm{Ca}$ content by adding the Ca content (Ca concentration $\times$ dry weight) of the leaves to that of the other parts (stems and roots). The whole-plant Ca content was divided by the whole-plant mass, whereby total Ca concentration was obtained.

\subsection{Statistical Analysis}

Data were analyzed using SPSS v. 22.0 (IBM Corp. Japan, Tokyo, Japan). In order to determine the effect of humidity on tipburn severity and plant growth in each lisianthus cultivar, differences in means were evaluated with a Student's $t$-test.

\section{Results and Discussion}

\subsection{Tipburn Severity}

In all figures and tables, cultivars were arranged in order of mean tipburn severity for the low and high air humidity treatments. For "Voyage pink" (VP) and "Azuma-no-kaori" (AK), which were the top two cultivars in terms of mean tipburn severity, their tipburn severity under the high humidity treatment was significantly higher than that in the low humidity treatment (Figure 1). In contrast, there was no significant difference in tipburn severity between treatments in the other five cultivars. 


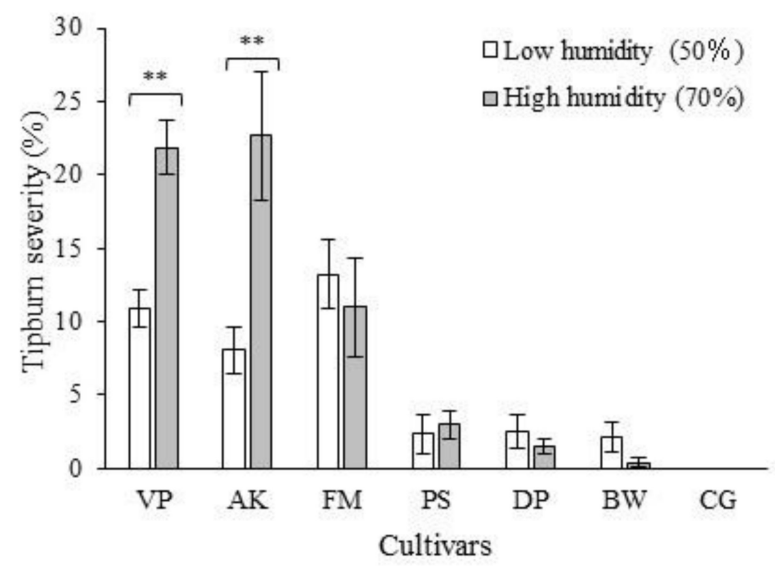

Figure 1. Mean tipburn severity in seven lisianthus cultivars (VP: "Voyage pink", AK: “Azuma-no-kaori", FM: "Fuyu-no-maria", PS: "Piccolosa snow", DP: "Diamond peach", BW: "Bolero white", and CG: "Celeb green") under low and high air humidity treatments. Cultivars are arranged in order of mean tipburn severity for the low and high humidity treatments. Error bars represent SE (Standard Error; $n=12$ ). * Represents significant differences between results for the low and high humidity treatments (Student's $t$-test: ${ }^{* *} p<0.01$ ).

Islam et al. [16] report that tipburn severity in lisianthus increases with increasing relative air humidity, based on the results of only two cultivars ("Kyoto Yellow" and "Echo Blue"). However, our results demonstrate that the influence of relative air humidity on tipburn severity in lisianthus differs among cultivars, and high air humidity conditions do not always increase the tipburn severity in lisianthus cultivars.

\subsection{Plant Growth Rate}

Relative plant growth rates (RGRs) of the seven cultivars are shown in Figure 2. There was no significant difference between treatments in the RGR of any of the cultivars. Therefore, it is suggested that relative air humidity has little effect on plant growth rate in lisianthus cultivars. In addition, there was no significant correlation $(r=0.480 ; p=0.082)$ between the relative plant growth rate (Figure 2) and the tipburn severity (Figure 1 ) in this experiment. This result suggests that differences in plant growth rate among lisianthus cultivars are not associated with varietal differences in tipburn severity.

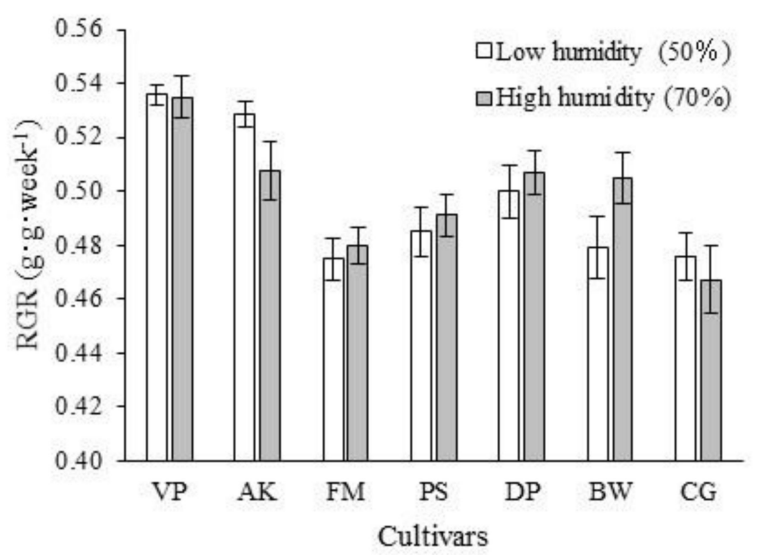

Figure 2. Mean relative growth rate (RGR) in seven lisianthus cultivars under low and high air humidity treatments. Cultivars are arranged in order of mean RGR for the low and high humidity treatments. Error bars represent SE $(n=12)$. 


\subsection{Transpiration Rate}

The transpiration rates of a leaf having the maximum area in a plant were significantly lower in the high humidity treatment than in the low humidity treatment for VP, "Fuyu-no-maria" (FM), PS. and "Bolero white" (BW) (Figure 3).

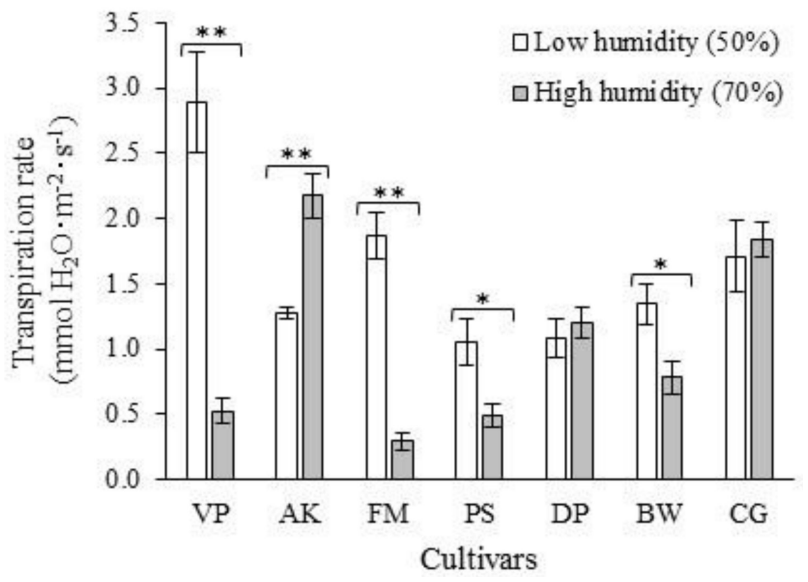

Figure 3. Mean transpiration rates of the maximum leaf in seven lisianthus cultivars under low and high air humidity treatments. Cultivars are arranged in order of mean transpiration rates for the low and high humidity treatments. Error bars represent SE $(n=12)$. ${ }^{*}$ Represents significant differences between results for the low and high humidity treatments (Student's $t$-test: ${ }^{*} p<0.05,{ }^{* *} p<0.01$ ).

Contrarily, there was no significant difference between treatments in the transpiration rate for the "Diamond peach" (DP) and "Celeb green" (CG) cultivars. The transpiration rate for AK was significantly higher under the high humidity treatment than under the low humidity treatment.

Although transpiration rates generally decrease with increasing relative air humidity, only half of the cultivars in our experiment showed such a decrease. This result suggests that the response of transpiration rate to relative air humidity also varies among cultivars.

\subsection{Ca Distribution}

Ca concentrations in each plant for the seven cultivars are shown in Table 2. Total Ca concentrations were significantly higher under the high humidity treatment than the low humidity treatment for all cultivars, except for PS. The Ca concentrations in the separate parts of the plant (upper leaves, lower leaves, tips of upper leaves, and base of upper leaves) of the FM, DP, BW, and CG were also significantly higher under the high humidity treatment than the low humidity treatment. For the other three cultivars (VP, AK, and PS), the Ca concentrations in the separate parts of the plant were either significantly higher under the high humidity treatment than the low humidity treatment, or were not significantly different. There were no significant correlations between the transpiration rate and the $\mathrm{Ca}$ concentrations in this experiment (total Ca concentration: $r=-0.202, p=0.489$; Ca concentration in upper leaves: $r=-0.449, p=0.108$; Ca concentration in lower leaves: $r=-0.273, p=0.346$ ). 
Table 2. Mean total Ca concentrations, Ca concentrations of upper and lower leaves, and Ca concentrations in the tips and bases of upper leaves in seven lisianthus cultivars under low $(50 \%)$ and high $(70 \%)$ air humidity treatments.

\begin{tabular}{|c|c|c|c|c|c|c|c|c|c|c|c|c|c|c|c|}
\hline \multirow{2}{*}{ Cultivars } & \multicolumn{3}{|c|}{$\begin{array}{c}\text { Total Ca Concentrations } \\
\text { (mg/g-DW) }\end{array}$} & \multicolumn{3}{|c|}{$\begin{array}{l}\text { Ca Concentrations in Upper } \\
\text { Leaves (mg/g-DW) }\end{array}$} & \multicolumn{3}{|c|}{$\begin{array}{l}\text { Ca Concentrations in Lower } \\
\text { Leaves }(\mathrm{mg} / \mathrm{g}-\mathrm{DW})\end{array}$} & \multicolumn{3}{|c|}{$\begin{array}{l}\text { Ca Concentrations in Tips of } \\
\text { Upper Leaves (mg/g-DW) }\end{array}$} & \multicolumn{3}{|c|}{$\begin{array}{l}\text { Ca concentrations in Bases of } \\
\text { Upper Leaves (mg/g-DW) }\end{array}$} \\
\hline & Low & High & & Low & High & & Low & High & & Low & High & & Low & High & \\
\hline VP & $5.2 \pm 0.1$ & $6.4 \pm 0.2$ & ** & $1.4 \pm 0.1$ & $2.0 \pm 0.1$ & $* *$ & $3.1 \pm 0.1$ & $4.1 \pm 0.1$ & ** & $1.3 \pm 0.1$ & $1.4 \pm 0.2$ & & $1.5 \pm 0.1$ & $2.1 \pm 0.1$ & $* *$ \\
\hline AK & $5.2 \pm 0.1$ & $6.5 \pm 0.2$ & ** & $2.5 \pm 0.1$ & $2.4 \pm 0.1$ & & $3.6 \pm 0.1$ & $4 \pm 0.1$ & * & $2.9 \pm 0.1$ & $2.8 \pm 0.2$ & & $2.4 \pm 0.1$ & $2.3 \pm 0.1$ & \\
\hline FM & $5.1 \pm 0.1$ & $6.7 \pm 0.3$ & ** & $2.2 \pm 0.1$ & $2.6 \pm 0.1$ & * & $2.9 \pm 0.1$ & $3.6 \pm 0.1$ & $* *$ & $2.0 \pm 0.1$ & $3.3 \pm 0.5$ & * & $2.2 \pm 0.1$ & $2.6 \pm 0.1$ & * \\
\hline PS & $5.3 \pm 0.2$ & $5.1 \pm 0.3$ & & $3.0 \pm 0.2$ & $2.6 \pm 0.2$ & & $4.3 \pm 0.2$ & $3.8 \pm 0.2$ & & $4.0 \pm 0.3$ & $3.6 \pm 0.3$ & & $2.8 \pm 0.2$ & $2.5 \pm 0.1$ & \\
\hline DP & $4.8 \pm 0.3$ & $6.8 \pm 0.3$ & $* *$ & $2.1 \pm 0.1$ & $2.7 \pm 0.1$ & $* *$ & $3.0 \pm 0.1$ & $3.9 \pm 0.1$ & $* *$ & $2.7 \pm 0.1$ & $4.8 \pm 0.3$ & ** & $1.9 \pm 0.1$ & $2.2 \pm 0.1$ & * \\
\hline BW & $5.1 \pm 0.2$ & $6.1 \pm 0.2$ & $* *$ & $2.2 \pm 0.1$ & $3.1 \pm 0.1$ & $* *$ & $3.1 \pm 0.1$ & $3.8 \pm 0.1$ & $* *$ & $3.2 \pm 0.1$ & $5.4 \pm 0.2$ & $* *$ & $2.0 \pm 0.1$ & $2.8 \pm 0.1$ & $* *$ \\
\hline CG & $4.7 \pm 0.1$ & $6.6 \pm 0.2$ & $* *$ & $2.3 \pm 0.1$ & $3.1 \pm 0.2$ & $* *$ & $3.5 \pm 0.1$ & $4.3 \pm 0.1$ & $* *$ & $3.4 \pm 0.2$ & $4.2 \pm 0.1$ & $* *$ & $2.2 \pm 0.0$ & $3.0 \pm 0.2$ & ** \\
\hline
\end{tabular}

Cultivars are arranged in order of mean tipburn severity for the low and high relative air humidity treatments. Data are means \pm SE $(n=12)$. ${ }^{*}$ Represents significant differences between results for the low and high air humidity treatments (Student's $t$-test: ${ }^{*} p<0.05,{ }^{* *} p<0.01$ ). 
These findings (except for AK) seem inconsistent with the transpiration rate results and earlier predictions that Ca transport in a plant body depends on transpiration. However, in strawberry plants, Bradfield and Guttridge [17] and Choi et al. [18] determined that foliar Ca concentrations under a high night air humidity treatment were significantly higher than those under a low night air humidity treatment, because root pressure increase under high night air humidity conditions. In addition, Ca concentrations in tomato fruits also increased when night conditions were humid $[19,20]$. The present results in lisianthus cultivars are in accordance with these findings. Therefore, it is suggested that $\mathrm{Ca}$ uptake from root pressure has a great influence on $\mathrm{Ca}$ acquisition and distribution in lisianthus cultivars.

Future research should investigate the influence of relative air humidity on plant water and nutrient flow in greater detail. Moreover, although all cultivars increased total and foliar Ca concentrations under high humidity conditions, they did not significantly decrease tipburn severity. The relevance of temporal plant growth rate and Ca distribution to the tipburn severity of lisianthus cultivars in different air humidity conditions should also be studied further.

\section{Conclusions}

Our experiment showed that high air humidity conditions did not always increase tipburn severity in lisianthus cultivars. Under the high air humidity treatment, the transpiration rates of all cultivars (except for AK) were either significantly lower than those under the low humidity treatment (VP, FM, PS and BW) or were not significantly different (DP and CG). However, total Ca concentrations in all cultivars (except for PS) under the high humidity treatment were significantly higher than those under the low humidity treatment. These results suggest that Ca uptake from root pressure in lisianthus cultivars has a great influence on their $\mathrm{Ca}$ acquisition and distribution. Future research should aim to elucidate the relevance of the physiological responses under different air humidity conditions to tipburn incidence in lisianthus cultivars, and sequential water and Ca flow under different air humidity conditions.

Author Contributions: All of the authors contributed to the work in the paper. T.K. and Y.W. designed the research and wrote the paper. Y.W. collected the data. H.W. and M.A. provided advice and suggestions. H.W. contributed to project supervision. All authors reviewed the manuscript.

Funding: This research received no external funding.

Conflicts of Interest: The authors declare no conflict of interest.

\section{References}

1. Ushio, A.; Hara, H.; Fukuta, N. Promotive effect of $\mathrm{CO}_{2}$ enrichment on plant growth and flowering of Eustoma grandiflorum (Raf.) Shinn. under a winter culture regime. J. Jpn. Soc. Hortic. Sci. 2014, 83, 59-63. [CrossRef]

2. Gaudreau, L.; Charbonneau, J.; Vézina, L.P.; Gosselin, A. Photoperiod and photosynthetic photon flux influence growth and quality of greenhouse-grown lettuce. HortScience 1994, 29, 1285-1289.

3. Tibbitts, T.W.; Rao, R.R. Light intensity and duration in the development of lettuce tipburn. Proc. Am. Soc. Hortic. Sci. 1968, 93, 454-461.

4. Kleemann, M. Effect of temperature on tipburn and boron deficiency in chervil. NJF-rapport nr. 2001, 329, 75-80.

5. Lee, J.G.; Choi, C.S.; Jang, Y.A.; Jang, S.W.; Lee, S.G.; Um, Y.C. Effects of air temperature and air flow rate control on the tipburn occurrence of leaf lettuce in a closed-type plant factory system. Hortic. Environ. Biotechnol. 2013, 54, 303-310. [CrossRef]

6. Goto, E.; Takakura, T. Prevention of lettuce tipburn by supplying air to inner leaves. Transactions ASAE 1992, 35, 641-645. [CrossRef]

7. Sago, Y. Effects of light intensity and growth rate on tipburn development and leaf calcium concentration in butterhead lettuce. HortScience 2016, 51, 1087-1091. [CrossRef]

8. Mason, G.F.; Guttridge, C.G. The influence of relative humidity and nutrition on leaf tipburn of strawberry. Sci. Hortic. 1975, 3, 339-349. [CrossRef]

9. Palzkill, D.A.; Tibbitts, T.W.; Struckmeyer, B.E. High relative humidity promotes tipburn on young cabbage plants. HortScience 1980, 15, 659-660. 
10. Choi, K.Y.; Lee, Y.B. Effects of relative humidity on the apparent variability in the incidence of tipburn symptom and distribution of mineral nutrients between morphologically different lettuce (Lactuca sativa L.) cultivars. Hortic. Environ. Biotechnol. 2008, 49, 20-24.

11. Kuronuma, T.; Watanabe, Y.; Ando, M.; Watanabe, H. Relevance of tipburn incidence to the competence for Ca acquirement and Ca distributivity in lisianthus (Eustoma grandiflorum (Raf.) Shinn.) cultivars. Sci. Hortic. under review.

12. Hunt, R. Plant Growth Curves: The Functional Approach to Plant Growth Analysis; Edward Arnold Ltd.: London, UK, 1982.

13. Collier, G.F.; Huntington, V.C. The relationship between leaf growth, calcium accumulation and distribution, and tipburn development in field-grown butterhead lettuce. Sci. Hortic. 1983, 21, 123-128. [CrossRef]

14. Cox, E.F.; McKee, J.M.T.; Dearman, A.S. The effect of growth rate on tipburn occurrence in lettuce. J. Hortic. Sci. 1976, 51, 297-309. [CrossRef]

15. Saure, M.C. Causes of the tipburn disorder in leaves of vegetables. Sci. Hortic. 1998, 76, 131-147. [CrossRef]

16. Islam, N.; Patil, G.G.; Torre, S.; Gislerød, H.R. Effects of relative air humidity, light, and calcium fertilization on tipburn and calcium content of the leaves of Eustoma grandiflorum (Raf.) Shinn. Eur. J. Hortic. Sci. 2004, 69, 29-36.

17. Bradfield, E.G.; Guttridge, C.G. The dependence of calcium transport and leaf tipburn in strawberry on relative humidity and nutrient solution concentration. Anal. Bot. 1979, 43, 363-372. [CrossRef]

18. Choi, J.H.; Chung, G.C.; Suh, S.R. Effect of night humidity on the vegetative growth and the mineral composition of tomato and strawberry plants. Sci. Hortic. 1997, 70, 293-299. [CrossRef]

19. Bradfield, E.G.; Guttridge, C.G. Effects of night-time humidity and nutrient solution concentration on the calcium content of tomato fruit. Sci. Hortic. 1984, 22, 207-217. [CrossRef]

20. Paraikovic, N.; Vinkovic, T.; Teklic, T.; Bilajac, R.; Tolušic, M. Influence of temperature and relative air humidity on calcium deficiency in tomato fruit (Lycopersicon esculentum Mill.). Agronomski Glasnik: Glasilo Hrvatskog Agronomskog Društva 2007, 69, 473-481.

(C) 2018 by the authors. Licensee MDPI, Basel, Switzerland. This article is an open access article distributed under the terms and conditions of the Creative Commons Attribution (CC BY) license (http:// creativecommons.org/licenses/by/4.0/). 